\title{
REGULARITIES OF INK-WATER BALANCE STABILITY IN OFFSET PRINTING
}

\author{
Olha Blagodir \\ Department of reprography \\ Publishing and Printing Institute of the National Technical University of Ukraine \\ "Kyiv Polytechnic Institute" \\ 1/37 Ak. Yangel str., Kiev, Ukraine, 03056 \\ o.blagodir@kpi.ua \\ Kateryna Zolotukhina \\ Department of reprography \\ Publishing and Printing Institute of the National Technical University of Ukraine \\ "Kyiv Polytechnic Institute" \\ 1/37 Ak. Yangel str., Kiev, Ukraine, 03056 \\ k.zolotukhina@kpi.ua \\ Bogdan Kushlyk \\ Department of reprography \\ Publishing and Printing Institute of the National Technical University of Ukraine \\ "Kyiv Polytechnic Institute" \\ 1/37 Ak. Yangel str., Kiev, Ukraine, 03056 \\ b.kushlyk@kpi.ua \\ Olena Velychko \\ Department of reprography \\ Publishing and Printing Institute of the National Technical University of Ukraine \\ "Kyiv Polytechnic Institute" \\ 1/37 Ak. Yangel str., Kiev, Ukraine, 03056 \\ o.velychko@kpi.ua
}

\begin{abstract}
Ink transfer onto the printed surface is provided by parameters as follows: dampening solution in ink emulsification level, dampening solution parameters as long as its ingredients and their exact dosing, dampening solution transfer features between fountain rollers, blanket and printing plate and printed material surface characteristics, thickness and volume of ink on the printing plate, level of ink setting on the imprint. Deviations in transfer from the optimal parameters cause the negative consequences. On the other hand there are hardly any new approaches in explanations of mutual influence of the technological environment parameters in the printing contact which results in lowering the printing process effectiveness while printing with minimal layers of ink-water emulsion.

In this article the mutual influence correlations of the printing contact technological environment characteristics are revealed, allowing operating the minimal layers of ink-water emulsion on high-productive machines while normalizing the color reproduction and imprints' quality.
\end{abstract}

Keywords: dampening solution, offset printing, ink-water emulsion, balance, imprint.

\section{Introduction}

The main technological parameters of the printing process which are significantly influencing the ink transfer characteristics are as follows: ink layer thickness on the printing plate, printing pressure, printing speed [1-5]. Besides that ink viscosity and its deviations in the printing process, ink register, microclimate in the printing factory, accordance of used printing plates, inks, printed material and printing equipment - all this is also influencing on the stability of the printing process itself and as refers the imprint also [6-11]. When the printing mode is rationally set it makes the 
image distortion on the imprint minimal. To make the imprints identical in the whole printrun the printing mode set should be stable.

In offset printing this is achieved when [1-3, 6, 8-11]: minimal required dampening solution and ink is supplied; optimal pressure between printing unit cylinders is set; $\mathrm{pH}$ and conductivity of the dampening solution is stable; printing ink parameters are stable and its setting is fixed; printed material humidity is not deviating and the accuracy of material supply in the printing zone is high enough; printing speed is stable.

Mentioned above printing process parameters are tightly correlated. Change of one leads to quality losses, color deviations [8, 10]. Graphic, gradient and color distortions on the imprint - that is mostly the fact caused by ink-water balance disproportion. The ink-water balance deviation is connected with the infractions of stable ink and fountain solution supply.

Nowadays there are different approaches to determine the ink transfer coefficient to the printed surface, there are equations, use of which may help in ink transfer process modeling. Nevertheless, mathematical equations are providing contradictory explanations of this phenomenon; in particular they do not take into account a lot of factors influencing this process. That is why modeling ink and water supply process is still an actual task.

\section{Materials and Methods}

Computer modeling of fountain solution transfer is made in a specialized software FLOW-3D v11.0.4. Statistic workout of the results was made in MS Excel 2010 software; modeling and calculations were made in MathLab 8.1 software.

As a printing element has got a determined space, it can be defined as a scalar field which should be transferred to the printing surface. The very idle printing element, or basically the amount of ink on it, can be described as shown in Fig. 1.

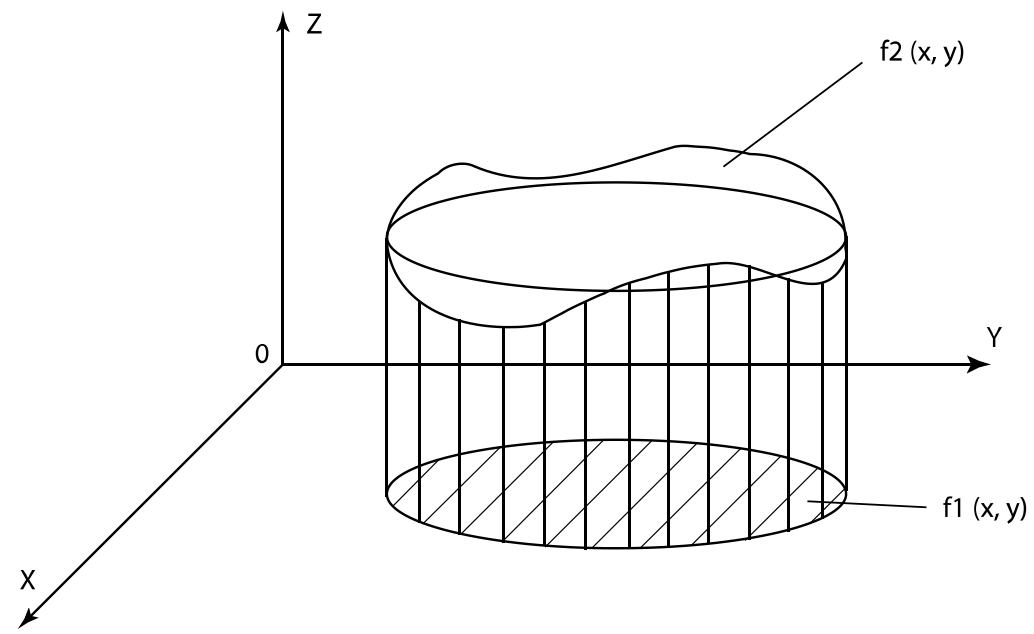

Fig. 1. The body (a printing element) (v), limited by the surface from top $(\Omega 2)$, equation of which is $z=f 2(x, y)$, and from below with a surface $(\Omega 1)$, equation of which is $z=f 1(x, y)$, and from the sides is limited by the cylindrical surface $(\Omega 3)$ generating lines of which are parallel to $\mathrm{OZ}$ axle

It is very important to solve the optimal operation search task, which may be applied to model the needed changes in ink and fountain solution supply to the printed element. The device doing a supply job may be called an emptying device on the beginning of the first contact zone, similarly the drain of the first contact zone which is a source for a second contact zone will be an emptying device for it. The task of searching the optimal operation should be solved in general taking into the fact that the stochasticity of the ink transfer indefinitely has got a delay. 


\section{Experimental modeling}

\section{1. Modeling the process of fountain solution transfer between two rollers}

The scheme of transfer between non-moving horizontal surface of a lower roller and the surface of an upper roller which is set on a fixed starting distance $c$ and is moving upwards is described in a Fig. 2. This model shows the process of fountain solution transfer between two rollers. To make the calculations easier modeling was conducted for axle symmetric type of this system that allowed lowering the number of calculations in twice. While modeling only the normal component of speed was used, as the displacement speed or rotating speed in terms of their very low influence could be neglected.

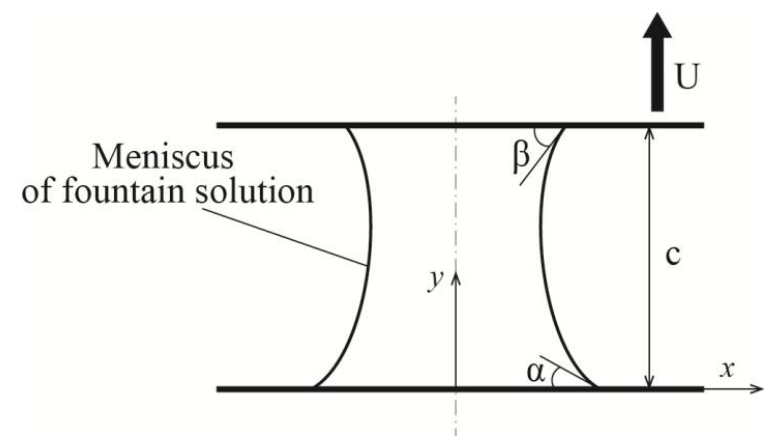

Fig. 2. Scheme of fountain solution transfer between two rollers

Process of fountain solution transfer between two rollers is being described by Navier-Stokes equations for the viscous fluid:

$$
\begin{gathered}
\frac{\partial \mathrm{u}}{\partial \mathrm{t}}=-(\mathrm{u} \cdot \nabla) \mathrm{u}+\mu \Delta \mathrm{u}-\frac{1}{\rho} \nabla \mathrm{P}+\mathrm{f}, \\
\nabla \cdot \mathrm{u}=0,
\end{gathered}
$$

where $\mathrm{u}$ - vector field of speeds, $\mu$ - viscosity, $\rho$ - density, $\mathrm{P}$ - pressure, $\mathrm{f}$ - vector field of mass forces, $\nabla$ - nabla operator, $\Delta$ - Laplace operator.

To solve these equations there are used the methods of ending-differential approximation to find the values of pressure and speed for every element of calculations network.

Modeling the free surfaces is a complex task in any calculation environment because such parameters of liquid flow as density, viscosity, speed and pressure are discrete and generally defined from a number of elements of a calculation network. Fountain solution zone is actually a Newton fluid with density $\rho$, viscosity $\mu$ and surface tension $\sigma$ available between two horizontal surfaces representing dampening rollers. As long as surrounding air has got low density and viscosity comparing to dampening solution it was not taken into consideration. This approach lowers the number of calculation, as because in most cases gas movement details are no matter in terms of movement of more complex dampening solution. While modeling in time $\mathrm{t}=0$ the system is described in a balanced situation, when the free surface is a static meniscus between two dampening rollers with static wetting angles $\alpha$ and $\beta$ correspondingly. Free surface becomes one of outer boundaries. Correct determination of boundary conditions on a free surface has got a significant impact on exact calculation of its dynamics. For this the Volume of Fluid method is used [12]. Its base is in a fractional function $\varphi-$ relative fluid volume. When $\varphi=1$ the volume is filled with liquid, when $\varphi=0$ - with gas. Free surface is a set of dots in which $0<\varphi<1$. The transfer equation for function $\varphi$ looks like:

$$
\frac{\partial \varphi}{\partial \mathrm{t}}+\mathrm{u} \cdot \nabla \varphi=0
$$

The surface tension force, formed between a cell and a printing form is described as follows:

$$
\mathrm{f}=\sigma \mathrm{kn}
$$


where $\sigma$ - coefficient of surface tension, $\mathrm{k}$ - average curvature for a free surface, $\mathrm{n}$ - unit normal vector of a free surface. $n$ and $\kappa$ are calculated as follows:

$$
\begin{aligned}
& \mathrm{n}=\frac{\nabla \varphi}{|\nabla \varphi|}, \\
& \mathrm{k}=-\nabla \cdot \mathrm{n} .
\end{aligned}
$$

Boundary sticking conditions are set for both rollers' surfaces. Because this model is symmetric, the boundary condition of symmetry is used for a line of plane centers, with this lowering calculations number by $50 \%$. Modeling zone is divided into square elements of a calculation network; in each of them the calculations of speed and tension are made.

Modeling was done while having such parameters set: dampening solution density $\rho=1000 \mathrm{~kg} / \mathrm{m}^{3}$, viscosity $\mu=0,001 \mathrm{~Pa} \cdot \mathrm{s}$, dampening solution volume $\mathrm{n}$ surface $\mathrm{V}=32 \mu \mathrm{m}^{2}$, surface tension coefficient $\sigma=0,072 \mathrm{H} / \mathrm{m}$, upper surface moving speed $U=0,1 \mathrm{~m} / \mathrm{s}$, surface tension angle of a roller $\beta=60^{\circ}$, starting distance between rollers $\mathrm{c}=8 \mu \mathrm{m}$.

Transfer coefficient is calculated as follows the equation (7):

$$
\mathrm{K}_{\mathrm{t}}=\frac{\mathrm{V}_{\mathrm{i}}}{\mathrm{V}}
$$

where $\mathrm{V}_{\mathrm{i}}$ - dampening solution volume transferred to an upper roller, $\mathrm{V}$ - total dampening solution volume between rollers.

Process of dividing the dampening solution between roller surfaces in different time moments is described in Fig. 3. The split of a dampening solution into two particles appeared on $55 \mu \mathrm{s}$. As the Fig. 3 shows, because of high tension and speed in the split point the additional drop appeared.

For the set research the dampening solution transfer coefficient onto upper roller is 0.45 .

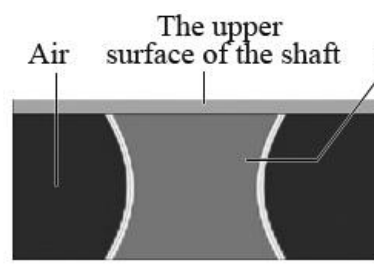

$\mathrm{t}=0$

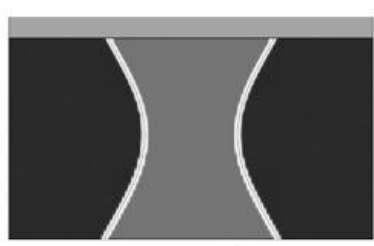

$\mathrm{t}=40 \mathrm{mks}$

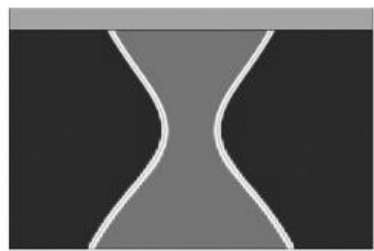

$\mathrm{t}=50 \mathrm{mks}$

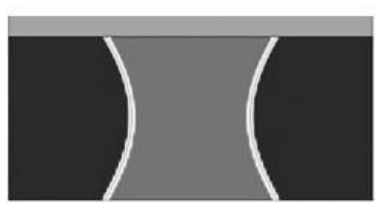

$\mathrm{t}=20 \mathrm{mks}$

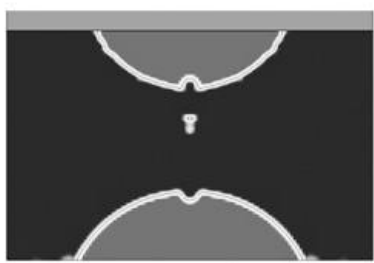

$\mathrm{t}=55 \mathrm{mks}$

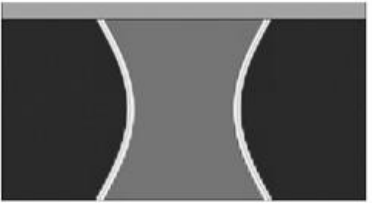

$\mathrm{t}=30 \mathrm{mks}$

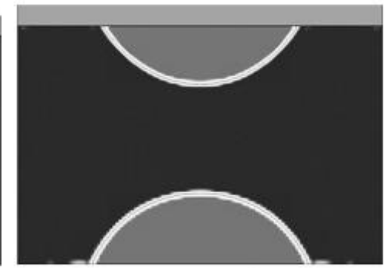

$\mathrm{t}=60 \mathrm{mks}$

Fig. 3. The type of dampening solution movement between two rollers while being divided onto two parts in different modeling time

\section{2. Mathematical model of ink-fountain adjustments}

Admitting the movement of the dot on the emptying device of the printing machine is described with the system of linear differential equations containing delays:

$$
\left\{\begin{array}{l}
\frac{\mathrm{dx}_{1}(\mathrm{t})}{\mathrm{dt}}=\mathrm{x}_{2}(\mathrm{t}), \\
\frac{\mathrm{dx} \mathrm{x}_{2}(\mathrm{t})}{\mathrm{dt}}=-\mathrm{x}_{1}(\mathrm{t}-\Delta)+\mathrm{U}(\mathrm{t}),
\end{array}\right.
$$


where sectionally continuous $\mathrm{U}(\mathrm{t})$ is limited by absolute value of $|\mathrm{U}(\mathrm{t})| \leq 1$, the delay $\Delta$ is constant: $\Delta=$ const. And the starting requirement is applied:

$$
\mathrm{x}_{1}(\mathrm{t})=0 \text { while } \mathrm{t} \in[-\Delta ; 0]
$$

Examining the phase limit as a condition of the moment of time availability $t 1>0$, when before reaching the point $(b, c)$ the followed inequality is accomplished:

$$
\mathrm{x}_{2}\left(\mathrm{t}_{1}\right) \leq 0 \text {. }
$$

The task of synthesis the optimal operation for the system of Eq. (8) including the limits Eqs. (9) and (10) may be solved with the help of construction the Hamiltonian corresponded to the system (8):

$$
\mathrm{H}=\Psi_{1}(\mathrm{t}) \cdot \mathrm{x}_{2}(\mathrm{t})-\Psi_{2}(\mathrm{t}) \cdot\left(\mathrm{x}_{1}(\mathrm{t}-\Delta)-\mathrm{U}(\mathrm{t})\right)
$$

and analyzing the suited for it system of equations with advance [13].

The most controlling objects in the printing equipment have got a clear transport delay, so it is actual developing and improvement the algorithm to operate the objects having a delay. On the very last timeline $t_{k}-\Delta<t \leq t_{k}$ the Hamiltonian (11) may be obtained in an easier look:

$$
\mathrm{H}=\mathrm{C}_{1} \mathrm{x}_{2}(\mathrm{t})-\mathrm{C}_{2}\left(\mathrm{x}_{1}(\mathrm{t}-\Delta)-\mathrm{u}(\mathrm{t})\right)
$$

According to Pontryagin's maximum principle the optimal operation $u(t)$ should provide the Hamiltonian with the maximum value:

$$
\mathrm{H}\left(\mathrm{x}_{1}, \mathrm{x}_{2}, \Psi_{1}, \Psi_{2}, \mathrm{u}\right) \rightarrow \max
$$

Base on Eq. (12), and the limit of control $|u(t)| \leq 1$, we get that on the last timeline $t_{k}-\Delta<t \leq t_{k}$ the optimal operation $\mathrm{u}(\mathrm{t})$ depends on the sign of the constant

$$
\mathrm{u}(\mathrm{t})=\operatorname{sign} \mathrm{C}_{2},
$$

so $\mathrm{u}(\mathrm{t})=1$, if $\mathrm{C} 2<0$ and $\mathrm{u}(\mathrm{t})=-1$, if $\mathrm{C} 2<0$. After making some mathematical transformations, the searched solution for Eq. (8) when $0<\mathrm{t} \leq \Delta$ is defined by the set of functions:

$$
\left\{\begin{array}{l}
\mathrm{x}_{1}(\mathrm{t})=\frac{1}{2} \mathrm{t}^{2}+\mathrm{at} \\
\mathrm{x}_{2}(\mathrm{t})=\mathrm{t}+\mathrm{a}
\end{array}\right.
$$

The Eq. (15) defines the dot's movement trajectory of the emptying device in the printing machine in parametric view. Making a transformation we may get this in an analytic view:

$$
\mathrm{x}_{1}=\frac{1}{2} \mathrm{x}_{2}{ }^{2}-\frac{\mathrm{a}^{2}}{2}
$$

So the movement trajectory from the starting point $\mathrm{t}=0$ up to the moment of time defined by the delay value $\mathrm{t}=\Delta$ is a part of a quadratic parabola, which can be shown on a graph in a phase flat $\{x 1, x 2\}$ (Fig. 4). If the set point (b, c) belongs to the line (16) when $a \leq x 2 \leq a+\Delta$, we may count the optimal operation search task as solved.

So, when the operation is $\mathrm{u}=-1$ the trajectory $(15)$ is changed with this:

$$
\left\{\begin{array}{l}
\mathrm{x}_{1}(\mathrm{t})=\mathrm{at}-\frac{1}{2} \mathrm{t}^{2} \\
\mathrm{x}_{2}(\mathrm{t})=\mathrm{a}-\mathrm{t} .
\end{array}\right.
$$




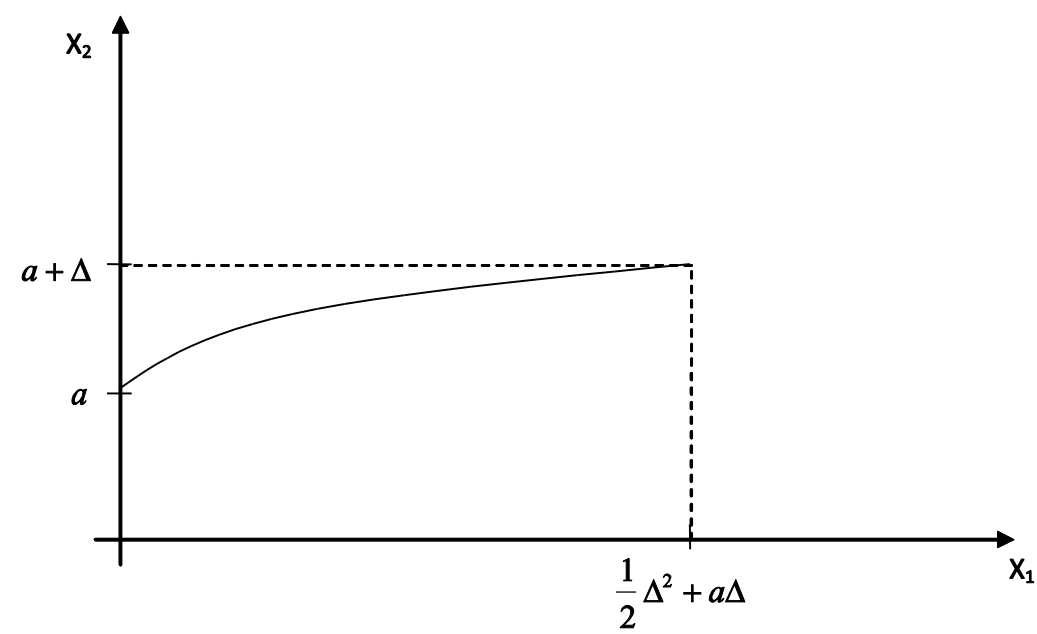

Fig. 4. The dot's movement trajectory of the emptying device starting from the firstly set moment of time which is defined by the delay according to the maximum available operation $\mathrm{u}=+1$

Such a trajectory written in parametric view also is a parabola but its formulae differ against Eq. (13) with the sign:

$$
\mathrm{x}_{1}=\frac{\mathrm{a}^{2}}{2}-\frac{1}{2} \mathrm{x}_{2}^{2},
$$

where a $-\Delta \leq \mathrm{x} 2 \leq \mathrm{a}$.

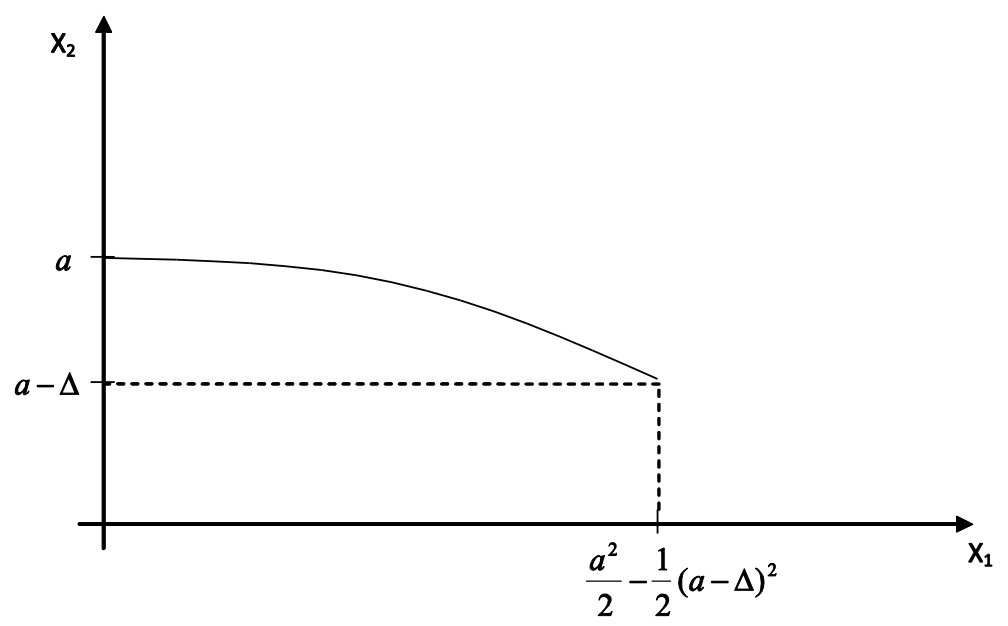

Fig. 5. The dot's movement trajectory of the machine's emptying device from the first time moment which is defined by the delay when having a minimum available operation $\mathrm{u}=-1$

If $\Delta<\mathrm{a}$, then the graphical view of this function is a part of parabola shown in Fig. 5.

\section{Results and discussion}

The provided theoretical research shows the availability to set the process of reaching and continuously keeping stable the ink/water balance, when having some values of ink and dampening solution supply according to the number (or total square) of this elements on the printing plate. The mechanism that may define the amount of ink and fountain solution which form an emulsion transferred to the substrate in the every idle printing element should be researched. When having some operating systems that may check and control the mentioned above values in the real-time mode the 
economic effect will be visual basically grounding on shortening waste on the start of the printing and on the machine's restarts after the technical or technological stops.

\section{Conclusions}

The process of dampening solution transfer between dampening rollers has been modeled.

The structure of a technological environment was improved. This contains oligomeric compounds and surface-active compounds to stabilize the ink-water balance, color parameters and to lower distortions while printing with hybrid inks and in-line coating in offset printing.

The regularities of stable ink-water balance in offset printing with hybrid inks were determined.

\section{References}

[1] Savchenko, K., Velychko, O. (2013). Printing inks' characteristics. Journal of Materials Science and Engineering, B 3 (7B), 464-468. Available at: http://www.davidpublisher.org/Public/uploads/Contribute/55b746ff45eae.pdf

[2] Kushlyk, B. (2011). An analysis of ink-water emulsion behavior in the process of offset printing with moistening of printing forms. Technology and Technique of Typography, 4, 34-45. Available at: http://ttdruk.vpi.kpi.ua/article/view/33485

[3] Zorenko, O. (2008). Dekel in the offset printing process. Kyiv: PPC «Kyiv University», 240.

[4] Helmut, Kipphan (2001). Handbook of Print Media.Technologies and Production Methods. doi: 1007/978-3-540-29900-4

[5] Blagodir, O. (2015). Analysis of configuration surfaces anilox rollers in short inks printing systems. Proceedings, 1 (50), 57-63. Available at: http://nz.uad.lviv.ua/uk/articles/analysis-of-the-anilox-roller-surface-configuration-in-short-inking-systems/

[6] Dobritsina, R., Kotova, G. (2006). Methods for evaluating the interaction of dampening solutions with inks. Polygraphy, 5. Available at: http://www.polimag.ru/journal.php?j=38\&t=730\&PHPSESSID=51a

[7] Nechiporenko, N. A., Berdovschikova, A. V., Bozojan, M. A. (2013). The choice of the concentrate and to determine the optimal formulation of fountain solution for sheetfed offset printing. Proceedings of the higher educational institutions. Problems of printing and publishing, 6, 30-42.

[8] Zorenko, Y. (2015). Halftone Imprint's parameters in modern methods of color reproduction. Technology and Technique of Typography, 1 (47), 24-29. Available at: http://ttdruk.vpi.kpi.ua/article/view/43270/39737

[9] Nechiporenko, N. A, Shelud'ko, S. A, Berdovschikova, A. V. (2012). Technological aspects of offset printing on metallic substrates without thermal drying. Technology and Technique of Typography, 1 (35), 18-31.

[10] Zorenko, Y. (2015). Reproduction Technologies of offset printing. Kyiv: PPC «Kyiv University», 176.

[11] Skyba, V. (2015). Printing stability of offset printing plates. Technology and Technique of Typography, 1 (47), 30-39. Available at: http://ttdruk.vpi.kpi.ua/article/view/43272/39745

[12] Huang, W.-X., Lee, S.-H., Sung, H. J., Lee, T.-M., Kim, D.-S. (2008). Simulation of liquid transfer between separating walls for modeling micro-gravure-offset printing. International Journal of Heat and Fluid Flow, 29 (5), 1436-1446. doi: 10.1016/j.ijheatfluidflow.2008.07.002

[13] Kushlyk, B., Kushlyk-Dyvulska, O. (2010). The task of optimal operation with delays in mechanical movements of the printing equipment, in: Proceedings of the XIII International Conference Named after Academician M. Kravchuk, Ukraine, 239. 